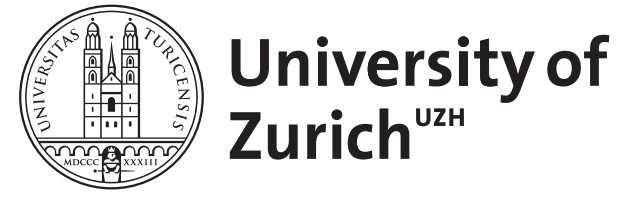

Book Review: D. Christopher Ralston; Justin Ho (Eds.): Philosophical Reflections on Disability

\author{
Felder, Franziska
}

DOI: https://doi.org/10.1007/s10677-010-9237-8

Posted at the Zurich Open Repository and Archive, University of Zurich ZORA URL: https://doi.org/10.5167/uzh-155698

Journal Article

Published Version

Originally published at:

Felder, Franziska (2011). Book Review: D. Christopher Ralston; Justin Ho (Eds.): Philosophical Reflections on Disability. Ethical Theory and Moral Practice, 14(2):247-249.

DOI: https://doi.org/10.1007/s10677-010-9237-8 


\title{
D. Christopher Ralston; Justin Ho (Eds.): Philosophical Reflections on Disability
}

\author{
Series: Philosophy and Medicine, Vol. 104, Dordrecht: Springer, \\ 2010, 263 pp., ISBN 978-90-481-2476-3, $€ 106.95$
}

\section{Franziska Felder}

Published online: 15 July 2010

(C) Springer Science+Business Media B.V. 2010

Given the fact that until very recently disability was dubbed a "philosopher's nightmare", to borrow a term by Licia Carlson (2010), the recent interest in disability issues is a welcome development. The volume at hand, edited by D. Christopher Ralston and Justin Ho, fits well in this development as it draws together some of the leading figures in medical ethics and bioethics. It seeks to offer a sample of competing theoretical and philosophical approaches to the conceptualization of disability by different scholars including Christopher Boorse, Anita Silvers, H. Tristam Engelhardt Jr, and Ron Amundson. Against the backdrop of competing theoretical and philosophical approaches, a number of issues are addressed: the interplay between disability and quality of life, questions of social justice and disability, and personal dimensions of the experience of disability. The book is divided in to four parts: Part one covers theories and concepts of disability and includes papers by Anita Silvers, Lennart Nordenfelt and Christopher Boorse. Part two addresses questions concerning disability, quality of life, and bioethics. The longest part of the book, with six papers, is dedicated to "disability, social justice, and public policy". The volume concludes with "personal voices" (part four), a paper by Jean Bethke Elshtain. As part of the book series "philosophy and medicine", its contributors are mainly from the field of bioethics and medical ethics.

Three main questions are tackled by the editors in their preface: First, how is disability defined and conceptualised? Second, what is the impact of disability on persons with disability? And last, how ought society to respond to disability? As these questions are connected, the volume tries to bridge the gap between abstract philosophical thinking and the pressing applied questions. In the introduction, the editors sort out the different approaches taken by the authors. It is one of the main advantages of the volume that in a helpful introduction, the editors point at the possible shortcomings of the different ways of looking at disability. This is especially helpful as it guides the reader through the way of different approaches tackled by the authors.

F. Felder $(\bowtie)$

Ethikzentrum der Universität Zürich, Graduiertenprogramm für Interdisziplinäre Ethikforschung,

Zollikerstrasse 115, 8008 Zürich, Switzerland

e-mail: felder@ethik.uzh.ch 
Unsurprisingly, given that most authors have their background in bioethics or medical ethics, the majority of contributors defend a concept of disability that could be called a medical, or, in the case of Torbjörn Tannsjö, a utilitarian model of disability. For Lennart Nordenfelt, H. Tristam Engelhardt Jr. and Christopher Boorse, disability is closely connected to ability: either as the counterpart of positive ability (Nordenfelt), as inability (Boorse), or as not having an expected ability (Engelhardt). For Torbjörn Tannsjö, disability is characterized by falling below a specified normal variation. For Robert M. Veatch, although admitting that the terminology is vague, disability includes "a wide range of organic and mental conditions". For Muireann Quigley and John Harris, a disability is a harmed condition that someone has a strong rational preference not to be in. Contrary to this majority, Anita Silvers and Ron Amundson, both of whom have roots in the disability movement, besides also being philosophers, defend a social model of disability.

It is not possible to discuss every article in detail, but let me give some hints about the advantages and shortcomings as I see them. The advantages of the edition surely lie in the broad scope towards disability and the way it is addressed and drawn together in the volume. The shortcomings do not concern the book itself or the work of the editors, but the way philosophy still addresses disability in a limited and often one-sided way. Let me explain this by highlighting two articles in the volume.

In a thought experiment, for instance, Anita Silvers invites us to imagine how a society would look like if most people, instead of only a few, would wheel instead of walk. In such a world, according to Silvers, instead of stairs, spiralling ramps would connect floors, every public transport vehicle would be completely accessible for wheelchair users, and so on. However, whereas this historical counterfactualization gives insight into social factors and is convincing for impairments where the social influences largely determine who becomes disabled and who not, it is not as convincing with regard to disabilities that are more associated with internal restrictions. To use the method of counterfactualization, what would a world look like where most people were severely cognitively disabled, people lacking a wide range of intrinsically valuable abilities? This would not only be a society with better access to goods, but it would be an entirely different society without any elaborated technology at all.

What Silvers is rightly pointing at, namely the social conditions and the structure of society, is missing in most other articles. It is slightly misleading to label most models presented in the volume as medical models. This term implies that there is a distinctive medical view on disability that can be distinguished from a social view. It is also the name of a view that should be overcome. However, most authors in the volume defend some form of individualistic or medical model of disability. Although not ignoring social aspects, they situate 'the problem' to a large degree in the individual. Such a view is defended, for instance, by Lennart Nordenfelt. Nordenfelt analyzes the concept of disability by considering its, in his view, counterpart, the concept of positive ability. Although Nordenfelt does not deny the role of external circumstances for a 'dis-ability' to develop, he limits the discussion to so called 'standard' and 'reasonable' circumstances. The first addresses the way the world 'normally is', the second addresses exceptional circumstances where someone fails to show a certain ability (e.g. the ability of a teacher to teach during the war in Iraq). Both figure as kind of excuses if someone lacks practical possibilities because of missing opportunities. The disadvantage of disability is, in Nordenfelt's model, the disadvantage of impaired ability. The proper remedy would be medical and educational treatment to restore as much functioning or abilities as possible. The problem with Nordenfelt's approach is that it tends to assume a linear and causal way from absent or reduced ability to disability, leaving out not only a more phenomenological side of 
disability (for instance, how does it feel being disabled?) but, more importantly, a range of social and circumstantial factors, that shape the experience of disabled people in a deeper sense. An approach that could tackle this, however, would look different. It would question the 'reasonable' circumstances in society and ask how this reasonableness came into the world. It would also critically ask how welcoming a society is in accepting difference. It would highlight how institutions of society disadvantage and stigmatize disabled people by narrowed views of 'accepted abilities', ways of showing functionings and so on.

So, where should the journey go after this volume? It should probably go to defend more elaborated social models that are, first, more suitable to capture a wider range of facts (for example, why people with the same medical conditions, the same abilities or the same level of normal species functioning do not develop the same disability) and, more importantly, address a wider range of moral problems around disability. More complex models would be equipped to address problems under the surface that are often not so much open discrimination, but marginalisation and negligence of much more subtle forms. It is exactly for this reason why it is so important to include disabled people's voices in order to understand their problems better, and empirical research on the complexities of disadvantages disabled people experience as well as what would make disabled people's lives better. Such philosophical approaches would also go much deeper in another sense. They would critically examine how we as a non-disabled majority perceive disability or disabled people, what place in society we offer them and how and what we think their contribution to society is. The gap in the philosophy of disability, as I see it, is to capture the complexity of processes that leave someone disabled. It is a task in the future to gain insights into how phenomenological and also empirical considerations relate to normative findings and, ultimately, to questions of social justice and bioethics. These, however, are questions for a future volume and should by no means belittle the merits of this volume. To sum up, it is a worthwhile addition to the flourishing literature in the philosophy of disability and an invaluable read for all those interested in philosophical issues around disability.

\section{References}

Carlson L (2010) The faces of intellectual disability - philosophical reflections. Indiana University Press, Bloomington 